\title{
Editorial
}

\section{Los retos del desarrollo sostenible}

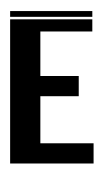

\author{
n junio, entre los días 20 y 22, se realizará en Río de aneiro, Brasil, la Confer encia \\ de las Naciones Unidas sobre Desarrollo Sostenible. Esta cumbre es, sin duda, \\ fundamental para que la comunidad mundial se manifieste en torno al tema \\ ambiental, el cual, en las circunstancias actuales, representa un elemento esencial \\ para su sobrevivencia.
}

El tema ambiental comienza a estudiarse por losteóricos del desarrollo económico, a partir delos años sesenta del siglo pasado, for mulan do las primeras propuestas sobredicha materia. Empero, para los mismos años, la preocupación por losfenómenos económicos, sociales y políticos, y su relación con el ambienteglobal o mundial, fueuna inquietud, en principio de biólogos, físicos y otros científicos. De hecho, empiezan a discutirse los efectos de la contaminación, la evidencia dealgunas crisis y aun de catástr ofes. Estosy otros problemas inducen a algunos países a volcarse sobrela problemática ambiental. D esde luego, la Organización de la Naciones Unidas (ONU) va a apoyar la celebración deeventos y reuniones para analizar dicha problemática. Es así como coordina la Conferencia de las Naciones Unidas sobreel M edio AmbienteH Humano, efectuada en Estocolmo en agosto de 1972. Dedicha conferencia surgió el Programa delas Naciones Unidas para el Medio Ambiente(PNUM A).

En los años setenta, el tema ambiental siguió siendo un tema importante, y, si bien es un asunto amplio y complejo queabarca difer entes disciplinas, desde el punto de vista económico, y, en particular, desde la perspectiva del desar rollo, surge un primer concepto relacionado con la temática: el ecodesarrollo. Esto representó un gran progreso. Por fin se reconocía, tanto por académicos como por organismos internacionales, hacia 1984, quelos avances a nivel mundial en términos de política ambiental, eran más bien modestos. Por ello, en 1987, las Naciones Unidas crear on la Comisión Mundial del Medio Ambiente y el Desarrollo, presidida por la primera ministra noruega, Gro Harlem Brundtland, eintegrada por personalidades de todas las regiones del mundo, portadoras de diferentes tendencias eideologías, con la misión de realizar un nuevo estudio sobre la situación existente.

Luego de tres años de análisis y de una serie de consultas y de diálogos en todos los niveles, se publicó un informeen el otoño de 1987 quesedenominó: "Nuestro Futuro Común". El documento fueaprobado por unanimidad y recogió el acuerdo más amplio existentehasta el momento, entre científicos y políticos del mundo entero. 
Este documento se considera un referente obligado para todas las decisiones posteriores relacionadas con el tema. El informe Brundtland fue la base para convocar la Conferencia de las Naciones Unidas sobre M edio Ambiente y Desarrollo, realizada en Río de Janeiro, en junio de 1992. En el informe, el concepto de sosteni bilidad ocupa un lugar sobresalientey se reconocela dificultad de definirlo de manera taxativa. Si bien se han enunciado varias definiciones, la de mayor aceptación esla queconsidera al desarrollo sostenible como aquel desarrollo que satisface las necesidades del presente, sin afectar la capacidad delasgeneraciones futuras para satisfacer las suyas.

La Cumbre de Río de 1992 definió los elementos necesarios para lograr un desarrollo económico quegar antice, al mismo tiempo, la eliminación de la pobreza y la inequidad, y la contención de la destrucción ambiental. De hecho, el objetivo antes mencionado está lejos de alcanzarse, a pesar de los logros obtenidos, pero en las circunstancias actuales cobra vigencia y, sin duda, se convierte en un compromiso ineludible por partedela dirigencia mundial con las generaciones presentes y futuras.

En la cumbre de hace veinte años se optó por reconocer la relevancia del tema ambiental por encima de los intereses económicos. En cambio, para la cumbre de junio de este año, el enfoque es diferente, debido a que se incorporará el concepto de economía verde, entendido como el intercambio comercial, que a la vez que produzca beneficios, disminuya las emisiones de gas carbónico y aprovechelosrecursos activamente, posibilitando la inclusión social. Seespera que en la Cumbre de Río de Janeiro de 2012, dada la agenda propuesta, no solo estén presentes ambiental istas, sino también economistas, inter esados en un futuro sostenible.

Las deliberaciones en torno a la economía verde, serán muy importantes, ya que este concepto retoma los aspectos centrales dela Cumbre deRío de 1992, como son: la equidad inter generacional y una concepción integral del desarrollo, en el sentido que incluye elementos económicos, sociales y ambientales. Al incluir el concepto de economía ver de en la cumbre del presente año, se corrobora el hecho que la economía es determinante en la sostenibilidad. Al insistir en una lógica económica, se dejan de lado otr os aspectos fundamentales del desar rollo, sosteniéndose, erróneamente, que para preservar el capital natural esnecesario mercantilizar los bienes públicos como la naturaleza. 